\section{Fertility and Reproductive Pathways of Triploid Flowering Pears (Pyrus sp.)}

\author{
Whitney D. Phillips ${ }^{1}$, Thomas G. Ranney ${ }^{2,5}$, Darren H. Touchell ${ }^{3}$,
} and Thomas A. Eaker ${ }^{4}$

Mountain Crop Improvement Lab, Department of Horticultural Science, Mountain Horticultural Crops Research and Extension Center, North Carolina State University, 455 Research Drive, Mills River, NC 287593423

Additional index words. aneuploidy, invasive, ornamental trees, polyploidy, reproductive biology, sterility

\begin{abstract}
Flowering pears are popular landscape plants due to a combination of desirable traits including broad adaptability, pest resistance, and attractive ornamental features. However, in some areas, flowering pears readily reseed and naturalize. Considering the value and utility of these trees, the development of infertile cultivars would be desirable. Breeding of triploid plants is one of the approaches that has been successfully used to develop seedless cultivars of many crops. The objective of this study was to evaluate female fertility and reproductive pathways of triploid flowering pear hybrids. Female fertility was characterized by evaluating fruit set, seeds per fruit, seed germination, seedlings per flower, and percent relative fertility [(seedlings per flower for triploid/ seedlings per flower for diploid control) $\times \mathbf{1 0 0}$ ]. Flow cytometry was used to determine relative genome sizes and ploidy levels of female parents, seedlings, and seeds (both embryo and endosperm) and to make inferences regarding reproductive pathways. Mean holoploid genome sizes were confirmed for the diploid [1.25 \pm 0.05 (SE) pg] and triploid $[1.88 \pm 0.12$ (SE) pg] female parents. Relative female fertility was significantly reduced in triploids, but varied considerably among accessions and ranged from $0.0 \%$ to $33.6 \%$. Of the 13 triploids used in this study, five accessions had a relative fertility of $<2 \%$. One accession had no measurable female fertility. Cytometric analysis of seeds and seedlings from triploid maternal parents showed that they were predominantly abnormal aneuploids, which typically results in seedlings with reduced fitness and fertility. Fertilization with unreduced gametes, apomixis, and pseudogamy were documented in triploid-derived embryos/offspring, but were relatively uncommon. The considerable reduction in female fertility of some triploid selections, coupled with the limited production of primarily aneuploid progeny, provides desirable options for new infertile flowering pears to prevent or reduce reseeding and naturalizing.
\end{abstract}

Pyrus (Rosaceae) contains $\approx 22$ species of trees originating from Asia, northern Africa, and Europe that have been cultivated extensively as both fruit and landscape plants (Challice, 1973). Pyrus calleryana was first introduced into cultivation by E.H. Wilson in

Received for publication 4 Apr. 2016. Accepted for publication 29 June 2016.

This research was funded, in part, by the North Carolina Agricultural Research Service, Raleigh, NC; the United States Department of Agriculture, Agricultural Research Service, Floriculture and Nursery Research Initiative, Washington, DC; the J. Frank Schmidt Family Foundation, Boring, OR; the North Carolina Biotechnology Center, Research Triangle Park, NC; and the Kenan Institute, Raleigh, NC.

We express our sincere thanks to Nathan Lynch, Joel Mowrey, Andra Nus, and the staff at the Mountain Horticultural Crops Research and Extension Center for their technical assistance.

${ }^{1}$ Graduate Research Assistant.

${ }^{2}$ JC Raulston Distinguished Professor.

${ }^{3}$ Research Scholar.

${ }^{4}$ Research Specialist.

${ }^{5}$ Corresponding author. E-mail: tom_ranney@ncsu. edu.

968 development of triploids. Triploids typically have low fertility due to a reproductive barrier whereby three sets of chromosomes cannot be divided evenly during meiosis yielding unbalanced segregation of chromosomes. Seedless bananas (Musa sp.), watermelons (Citrullus lanatus), and some citrus (Citrus sp.) are notable examples of triploid plants that have been purposefully developed to minimize seeds (Rounsaville, 2011). This approach has also been used to develop highly infertile triploid cultivars of various species that are valuable nursery crops, but potentially weedy in some environments, including trumpet vine (Campsis $\times$ tagliabuana) (Oates et al., 2014), tutsan (Hypericum androsaemum) (Trueblood et al., 2010), maiden grass (Miscanthus sinensis) (Rounsaville et al., 2011), and ruellia (Ruellia simplex) (Freyre and Moseley, 2012).

Triploids are typically highly infertile; however, limited fertility and seed production can result from the formation of apomictic embryos or through the union of aneuploid or unreduced gametes (Ramsey and Schemske, 1998; Rounsaville et al., 2011). Flow cytometric screening of seeds and/or seedlings can often elucidate these reproductive pathways (Eeckhaut et al., 2005; Matzk et al., 2000). Diploid plants, with standard sexual fertilization, form a $2 \mathrm{C}_{x}$ (diploid) embryo and $3 \mathrm{C}_{x}$ (triploid) endosperm, where $1 \mathrm{C}_{x}$ represents the monoploid genome size of one complete set of chromosomes. In gametophytic apomixis, the unreduced embryo sac and gametophyte develop autonomously, without fertilization, also forming a $2 \mathrm{C}_{x} \mathrm{em}$ bryo. However, the unreduced endosperm will have either a $4 \mathrm{C}_{x}$ cytotype (autonomous) or greater if fertilized (pseudogamous) (Barcaccia and Albertini, 2013; Koltunow et al., 2013). For triploids that undergo gametophytic apomixis, the embryo will be $3 C_{x}$ while the endosperm will be $6 C_{x}$ or greater. Although gametophytic apomixis involves nonreduction of the embryo sac, male gametes may also be unreduced in triploids producing $2 n$ pollen with a $3 \mathrm{C}_{x}$ cytotype (Ramsey and Schemske, 1998). Alternatively, aneuploids are a product of unbalanced chromosome segregation in meiosis and have either missing or extra individual chromosomes (Brownfield and Kohler, 2011). For triploids, these would result in gametes with $\approx 1.5 \mathrm{C}_{x}$ cytotypes, but potentially varying substantially.

Pyrus sp., including P. calleryana, have a base chromosome number of 17 and are primarily diploid $(2 n=2 x=34)$ with occasional triploid and tetraploid variants (Zielinski and Thompson, 1967). Researchers at the North Carolina State University's Mountain Crop Improvement Laboratory, Mills River, NC, developed a population of triploid Pyrus hybrids by crossing artificially induced tetraploids of $P$. calleryana with various diploid Pyrus taxa. The objective of this study was to evaluate fertility and reproductive pathways in newly developed triploid Pyrus hybrids for potential use as highly infertile alternatives to diploid cultivars. 


\section{Materials and Methods}

Plant materials. A population of triploid Pyrus hybrids was established in the field at the Mountain Horticultural Crops Research and Extension Center in Mills River, NC, in 2009. Thirteen triploids (Table 1) were selected from the population based on desirable traits including heavy flowering, desirable forms, absence of fire blight, and attractive fall color. Accession numbers beginning with H2008-048 have a parentage of $P$. calleryana H2002-031-012 (induced tetraploid) $\times$ Pyrus betulifolia 'Southworth'. The parentage of accessions beginning with H2008-049 is hybrid of $P$. calleryana $\mathrm{H} 2002-031-010$ (induced tetraploid) $\times P$. 'Silverball'. H2008-047-008 has a parentage of $P$. calleryana $\mathrm{H} 2002-031$ 001 (induced tetraploid) $\times$ Pyrus pyrifolia 'Ohara Beni'. Parental plants with H2002-031 accession numbers are artificially induced tetraploids of open-pollinated $P$. calleryana 'Bradford'. Three diploid plants were included in the field as controls and pollinators: H2001-008 open-pollinated seedling from $[$ Pyrus fauriei $\times(P$. betulifolia $\times P$. calleryana $)]\}$, H2001-043 \{open-pollinated seedling of $[(P$. calleryana $\times P$. fauriei $) \times$ Pyrus salicifolia]\}, and H2001-056 \{openpollinated seedling of $[P$. fauriei $\times$ Pyrus dimorphylla]\} (Table 1). Six additional interspecific hybrids were also interspersed with the triploids. Plants were completely randomized.

Evaluating female fertility. At flowering, three branches (evenly distributed around the perimeter) were selected on each tree, and the number of flowers $(\approx 100)$ was counted on each branch in Spring 2014. Fruit were collected at maturity (October), counted, and seeds were extracted. Seeds were stratified for $90 \mathrm{~d}$ at $4{ }^{\circ} \mathrm{C}$, and then moved to a greenhouse at $18-21{ }^{\circ} \mathrm{C}$ for $90 \mathrm{~d}$ to determine the number of viable seedlings that germinated.

Female fertility was determined based on fruit set $(\%)$, number of seeds per fruit, number of seed that germinated (\%), number of seedlings per flower, and relative fertility. Relative fertility was determined by comparing the number of seedlings per flower of a triploid to the most fertile diploid control.

Flow cytometry. Flow cytometry was used to determine the genome size (DNA content) and ploidy of parents, seedlings, and seeds, and the reproductive pathways following the methods of Gillooly and Ranney (2015) and terminology of Greilhuber et al. (2005). Four seedlings (randomly selected from the seedlings germinated during the female fertility study) and five seeds (collected separately from each tree, seedcoats were removed before testing) were sampled for each female parent, if available.

Plant tissue was placed in a $55-\mathrm{mm}$ plastic petri dish, along with $0.5-\mathrm{cm}^{2}$ Pisum sativum L. 'Ctirad' leaf tissue, an internal standard with known genome size of $2 \mathrm{C}=9.09 \mathrm{pg}$. Then, $400 \mu \mathrm{L}$ of extraction buffer (CyStain UV Precise P nuclei extraction buffer; Partec, Munster, Germany) was added to the petri

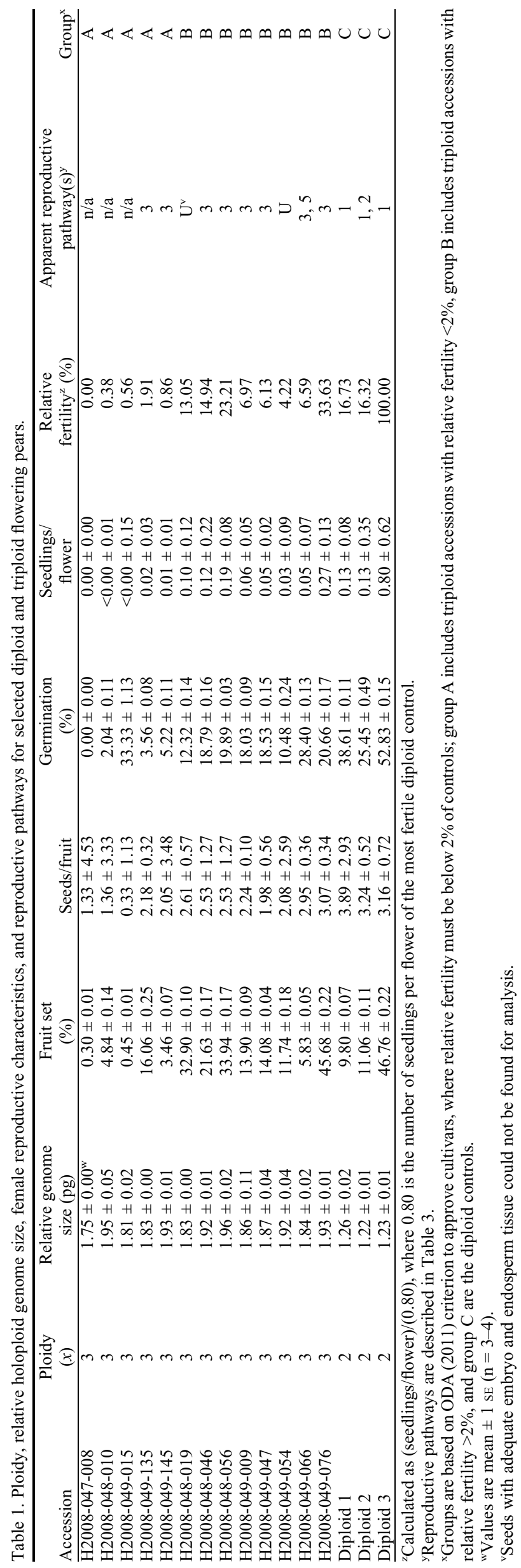


dish. Material was finely chopped for 30 to $60 \mathrm{~s}$ with a razor blade and incubated at room temperature for $\approx 30$ to $300 \mathrm{~s}$. The suspension was filtered through Partec 50- $\mu \mathrm{m}$ CellTrics disposable filters into a sample tube. Nuclei were stained with $1.6 \mathrm{~mL}$ of $4^{\prime}$,6-diamindino2-phenylindole. Samples were again incubated for 30 to $60 \mathrm{~s}$. Nuclei were analyzed using a flow cytometer (Partec PA II) with the blue florescence channel. Genome sizes of samples were calculated as: (mean florescence of unknown/mean florescence of known standard) $\times$ genome size of known standard.

Data analysis was conducted using analysis of variance (Proc GLM, SAS 9.3; SAS Institute Inc.). Mean separations for ploidy and fertility classes were conducted using the Waller-Duncan K-ratio $t$ test.

\section{Results and Discussion}

Genome sizes. Mean holoploid genome size of the diploid cytotypes was $1.25 \pm 0.05$ (SE) pg while the mean for triploids was $1.88 \pm$ 0.12 (SE) pg, $\approx 50 \%$ greater, consistent with having three sets of chromosomes (Table 1). The tetraploid parents had a mean genome size of $2.63 \pm 0.06(\mathrm{sE}) \mathrm{pg}$. These values are similar to those presented by Dickson et al. (1992) for $P$. calleryana with a $1 \mathrm{C}_{\mathrm{x}}$ genome size of $0.63 \mathrm{pg}$.

Female fertility. Fruit set, seeds per fruit, germination, seedlings per flower, and relative fertility varied considerably among individual triploid clones and diploid controls (Table 1). Many triploids had reduced fertility that resulted from a reduction in different components of female fertility. For example, some triploid accessions had very low fruit set (e.g., H2008-047-008, 0.3\%), low seeds per fruit (e.g., H2008-049-015, 0.33 seeds/ fruit) and/or low germination (e.g., H2008048-010, 2.04\% germination).

Relative female fertility represents the number of seedlings germinated per flower, relative to the most fertile diploid control, diploid 3 . Relative fertility among the triploids ranged from $0.00 \%$ to $33.63 \%$. Of the 13 triploids used in this study, five accessions had a relative fertility of $<2 \%$. One accession, H2008-047008 , had no measurable female fertility.

Although absolute sterility is difficult to achieve and/or document (i.e., difficulty in proving a negative), a common approach has been to set a limit for an acceptable level of fertility. For example, the Oregon Department of Agriculture (ODA) (2011) considers cultivars of Buddleia that produce less than $2 \%$ viable seeds (i.e., $98 \%$ reduction in female fertility relative to a standard fertile cultivar) to be sufficiently infertile for placement on an ODA-approved list for propagation, transportation, and sale in Oregon. Triploid pear hybrids in this study that met that criterion were categorized in group A (Tables 1 and 2), while triploid hybrids that did not meet this criterion were categorized in group B. Diploid controls were designated as group C. Comparing these three groups (Table 2) showed no significant difference in percent fruit set. However, the number of seeds per fruit was significantly different between all three groups with group A having the least number of seeds and group $C$ having the most. Groups A and B (all confirmed triploids) were significantly lower than group $\mathrm{C}$ (diploid controls) for germination percent, number of seedlings per flower, and relative fertility. These results indicate that some triploids had very low fertility, due to low number of seeds per fruit and low germination, even though they produced some fruit.

Reproductive pathways. The diploid maternal parents produced offspring with genome sizes consistent with diploids or slightly below (Fig. 1). The progeny from maternal triploids was variable with holoploid genome sizes ranging from 1.35 to $3.11 \mathrm{pg}$, with a mean of $1.70 \mathrm{pg}$. The majority $(90 \%)$ of the triploid progeny had a genome size near a triploid level or between diploid and triploid levels, which indicated that these parents were producing predominantly abnormal aneuploid gametes. Aneuploids typically have reduced fitness and fertility and can suffer from abnormal development (Ramsey and Schemske, 1998). However, a few progeny (4\%) from maternal triploids had genome sizes near diploid levels, indicating that a generational reversion to a diploid or near diploid cytotype may be possible in limited instances. A limited number of progeny $(6 \%)$ had genome sizes greater than triploid, including near tetraploid and above. This result indicated some fertilization from unreduced gametes from one or both parents.

Flow cytometry of seeds from openpollinated diploid maternal parents demonstrated a range of reproductive pathways with both asexual and sexual modes (Tables 1 and 3; Fig. 1). Most seeds from diploid maternal parents demonstrated standard sexual fertilization of a reduced embryo sac $\left(1 \mathrm{C}_{x}\right.$ egg and $2 \mathrm{C}_{x}$ polar nuclei) by reduced male gametes $\left(1 \mathrm{C}_{x}\right.$ ) (pathway 1 , Table 3 ). However, one seed from a diploid maternal parent had a $2 \mathrm{C}_{x} / 6 \mathrm{C}_{x}$ embryo/endosperm cytotype, indicating an unreduced and unfertilized embryo and unreduced polar nuclei fertilized by an unreduced male gamete (pathway 2, Table 3), a form of apomixis/pseudogamy.

Seeds from open-pollinated triploid maternal parents also demonstrated multiple reproductive pathways. Most of the seeds from triploid females appeared to form by fertilization of a reduced aneuploid embryo sac $\left(\approx 1.5 \mathrm{C}_{x}\right.$ egg and $\approx 3 \mathrm{C}_{x}$ polar nuclei $)$ by reduced, aneuploid male gametes $(\approx 1.5 \mathrm{C})$

Table 2. Female reproductive characteristics for select groups of diploid and triploid hybrids.

\begin{tabular}{|c|c|c|c|c|c|c|}
\hline Group $^{2}$ & $\mathrm{n}$ & Fruit set (\%) & Seeds/fruit & Germination (\%) & Seedlings/flower & Relative fertility (\%) \\
\hline$\overline{\mathrm{A}}$ & 5 & $5.0 \mathrm{a}^{\mathrm{y}}$ & $1.5 \mathrm{a}$ & $8.8 \mathrm{a}$ & $0.006 \mathrm{a}$ & $0.74 \mathrm{a}$ \\
\hline B & 8 & $22.4 \mathrm{a}$ & $2.5 \mathrm{~b}$ & $18.4 \mathrm{a}$ & $0.109 \mathrm{a}$ & $13.59 \mathrm{a}$ \\
\hline $\mathrm{C}$ & 3 & $22.5 \mathrm{a}$ & $3.4 \mathrm{c}$ & $39.8 \mathrm{~b}$ & $0.353 \mathrm{~b}$ & $44.35 \mathrm{~b}$ \\
\hline \multicolumn{7}{|c|}{ Analysis of variance ( $P$ value $)$} \\
\hline
\end{tabular}

${ }^{\mathrm{z}}$ Group A includes triploid accessions with relative fertility $<2 \%$, group B includes triploid accessions with relative fertility $\geq 2 \%$, and group $\mathrm{C}$ are diploid controls.

${ }^{y}$ Mean followed by the same letter within a column are not significantly different based on Waller-Duncan K-ratio $t$ test, $P<0.05$.

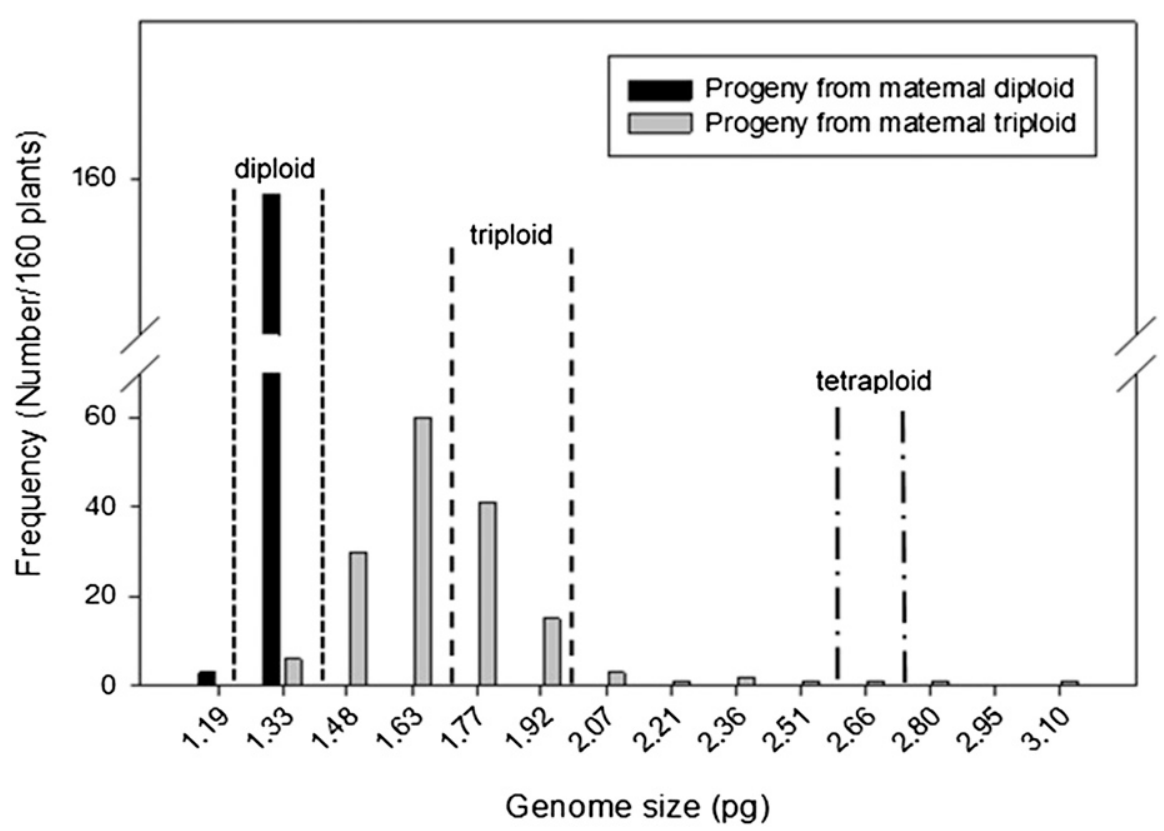

Fig. 1. Frequency distribution of holoploid genome sizes of seedlings derived from open-pollinated diploid and triploid Pyrus cytotypes. Gate width for columns (dashed vertical lines) was based on a $95 \%$ prediction interval for diploid, triploid, and tetraploid parents calculated as the mean $\pm 1.96 \mathrm{SE}$. 
Table 3. Probable reproductive pathways from open-pollinated seeds and seedlings of diploid and triploid maternal Pyrus hybrids.

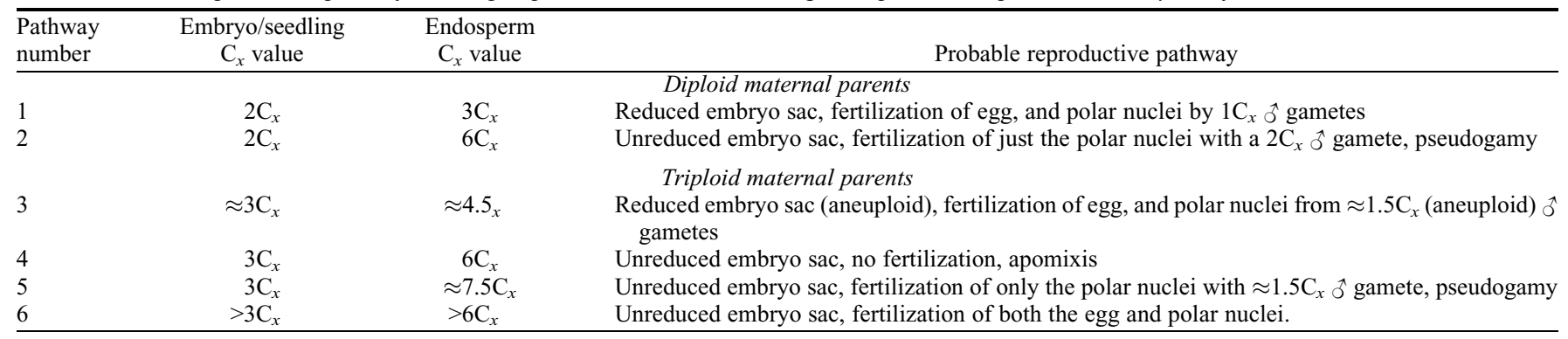

resulting in an $\approx 3 \mathrm{C}_{x}$ embryo and $\approx 4.5 \mathrm{C}_{x}$ endosperm (pathway 3, Table 3). In one instance, a triploid maternal parent produced a $3 \mathrm{C}_{x} / 6 \mathrm{C}_{x}$ embryo/endosperm cytotype indicating an apomictic origin from an unreduced embryo sac without fertilization (pathway 4, Table 3). There was also one instance of a $3 \mathrm{C}_{x} / \approx 7.5 \mathrm{C}_{x}$ embryo/endosperm cytotype indicating an unreduced embryo sac with fertilization of just the polar nuclei by a reduced, aneuploid male gamete $\left(\approx 1.5 \mathrm{C}_{x}\right)$. Analysis of seedlings also showed occasional fertilization by unreduced gametes, as previously mentioned (based on seedlings with ploidy higher than triploid, including near tetraploid and above).

Using triploids as a means to minimize fertility of weedy species has been successful in many species. The development of triploid $M$. sinensis, $H$. androsaemum, and Campsis 'Chastity' showed reduction in relative fertility often exceeding 98\% (Oates et al., 2014; Rounsaville et al., 2011; Trueblood et al., 2010). Similar to the present study, the limited seedlings that arose from triploid maternal $M$. sinensis were also mostly aneuploids (Rounsaville et al., 2011). Ranney et al. (2004) researched on reproductive pathways in diploid and triploid flowering crabapples (Malus sp.), also in Rosaceae, and documented pseudogamy, aneuploidy, unreduced gametes, and some apomictic embryos.

In conclusion, this study documented that many triploid flowering pear cytotypes displayed a substantial reduction in fertility (as much as $100 \%$ ). However, it is also important to consider the fitness and cytogenetics of any seedlings that are produced. Of the limited seedlings that were derived from triploid maternal parents, most were abnormal aneuploids with the infrequent production of some apparent isoploids/euploids ( $2 x$ and $4 x$ ). Flow cytometry of seeds and seedlings from some triploid maternal parents showed a low frequency of multiple reproductive pathways including standard double fertilization with reduced aneuploid gametes, fertilization with unreduced gametes, apomixis, and pseudogamy. These results indicate that selection of highly infertile triploid cultivars is a viable approach to reduce or eliminate the selfsowing of flowering pears in the landscape.

\section{Literature Cited}

Barcaccia, G. and E. Albertini. 2013. Apomixis in plant reproduction: A novel perspective on an old dilemma. Plant Reprod. 26:159-179.

Bell, A.C., T.G. Ranney, and T.A. Eaker. 2004. Resistance to fire blight among flowering pears and quince. HortScience 40:413-415.

Brownfield, L. and C. Kohler. 2011. Unreduced gamete formation in plants: Mechanisms and prospects. J. Expt. Bot. 62(5):1659-1688.

Challice, J.S. 1973. Numerical taxonomic studies of the genus Pyrus using both chemical and botanical characters. Bot. J. Linn. Soc. 67(2): 121-148.

Dickson, E.E., K. Arumuganathan, S. Kresovich, and J.J. Doyle. 1992. Nuclear DNA content variation within the Rosaceae. Amer. J. Bot. 79:1081-1086.

Dirr, M.A. 1998. Manual of woody landscape plants: Their identification, ornamental characteristics, culture, propagation, and uses. 6th ed. Stipes Publishing, Champaign, IL.

Eeckhaut, T., L. Leus, and J.V. Huylenbroeck 2005. Exploitation of flow cytometry for plant breeding. Acta Physiol. Plant. 27(4B):743750

Freyre, R. and A. Moseley. 2012. Fruitless Ruellia simplex R10-102 ('Mayan Purple') and R10-08 ('Mayan White'). HortScience 47:1808-1814.

Gillooly, D.A. and T.G. Ranney. 2015. Genome sizes and ploidy levels in the genus Kalmia. HortScience 50:1426-1428.

Greilhuber, J., J. Doežel, M.A. Lysák, and M.D. Bennett. 2005. The origin, evolution and proposed stabilization of the terms 'genome size' and ' $\mathrm{C}$-value' to describe nuclear DNA contents. Ann. Bot. (Lond.) 95:255-260.

Koltunow, A.M.G., P. Ozias-Akins, and I. Siddiqi. 2013. Apomixis, p. 83-110. In: P.W. Becraft (ed.). Seed genomics. Wiley-Blackwell, Oxford, UK.
Matzk, F., A. Meister, and I. Schubert. 2000. An efficient screen for reproductive pathways using mature seeds of monocots and dicots. Plant J. 21(1):97-108.

Oates, K.M., T.G. Ranney, and D.H. Touchell. 2014. Campsis Xtagliabuana 'Chastity': A highly infertile triploid trumpet vine. HortScience 49:343-345.

Oregon Department of Agriculture (ODA). 2011. Screening of Buddleja cultivars applying for exemption under amended version of OAR 603 052-1200. 19 Feb. 2016. <http://www.oregon. gov/ODA/shared/Documents/Publications/ NurseryChristmasTree/BuddlejaScreening.pdf $>$.

Ramsey, J. and D.W. Schemske. 1998. Pathways, mechanisms, and rates of polyploid formation in flowering plants. Annu. Rev. Ecol. Syst. 29:467-501.

Ranney, T.G., T.A. Eaker, N.P. Lynch, and R.T. Olsen. 2004. Reproductive pathways among flowering crabapples. SNA Res. Conf. 49:575579.

Rounsaville, T.J. 2011. Cytogenetics, micropropagation, and reproductive biology of Berberis, Mahonia, and Miscanthus. North Carolina State Univ., Raleigh, MS Thesis.

Rounsaville, T.J., D.H. Touchell, and T.G. Ranney. 2011. Fertility and reproductive pathways in diploid and triploid Miscanthus sinensis. HortScience 46:1353-1357.

Santamour, F.S. and A.J. McArdle. 1983. Checklist of cultivars of callery pear (Pyrus calleryana). J. Arboric. 9(4):114-116.

Swearingen, J., B. Slattery, K. Reshetiloff, and S. Zwicker. 2010. Plant invaders of Mid-Atlantic natural areas. 4th ed. Natl. Park Serv. and U.S. Fish and Wildlife Serv., Washington, DC.

Trueblood, C.E., T.G. Ranney, and N.P. Lynch. 2010. Evaluating fertility of triploid clones of Hypericum androsaemum L. for use as non-invasive landscape plants. HortScience 45:1026-1028.

Vincent, M.A. 2005. On the spread and current distribution of Pyrus calleryana in the United States. Southern Appalachian Bot. Soc. 70(1): 20-31.

Zielinski, Q.B. and M.M. Thompson. 1967. Speciation in Pyrus: Chromosome number and meiotic behavior. Bot. Gaz. 128(2):109-112. 